\title{
Title: Prevalence and correlates of prescription opioid residue injection
}

\author{
Élise Roy ${ }^{\mathrm{a}, \mathrm{b}}$ (Corresponding author) \\ Nelson Arruda ${ }^{a}$ \\ Karine Bertrand ${ }^{\mathrm{a}}$ \\ Magali Dufour ${ }^{\mathrm{a}}$ \\ Émélie Laverdière ${ }^{\mathrm{a}}$ \\ Didier Jutras-Aswad ${ }^{\mathrm{c}, \mathrm{d}}$ \\ Michel Perreault ${ }^{\mathrm{e}, \mathrm{f}}$ \\ Djamal Berbiche ${ }^{\mathrm{g}}$ \\ Julie Bruneau ${ }^{\mathrm{c}, \mathrm{h}}$
}

${ }^{a}$ Faculty of Medecine and Health Sciences, Université de Sherbrooke, Longueuil, Québec, Canada

${ }^{\mathrm{b}}$ Institut national de santé publique du Québec, Montréal, Québec, Canada

'Research Centre, Centre Hospitalier de l'Université de Montréal (CRCHUM), Montréal, Québec, Canada

${ }^{\mathrm{d}}$ Department of Psychiatry, Université de Montréal, Montréal, Québec, Canada

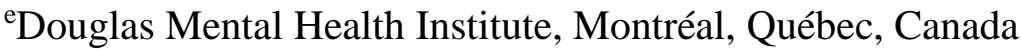

fDepartment of Psychiatry, McGill University, Montréal, Québec, Canada

${ }^{g}$ Faculty of Medecine and Health Sciences, Charles-Le Moyne Hospital Research Centre, Longueuil, Québec, Canada

${ }^{\text {h}}$ Department of Family Medecine, Université de Montréal, Montréal, Québec, Canada

Address correspondance to : Élise Roy, Faculté de médecine et des sciences de la santé, Université de Sherbrooke, Campus de Longueuil, 150 Place Charles-Le Moyne, room 200. Longueuil, Québec, Canada. J4K 0A8. E.mail : Elise.Roy@USherbrooke.ca 


\begin{abstract}
Background: There is growing evidence of intravenous administration of prescription opioids (POs) in several countries. Preparation of POs for injection may leave residues in containers and filters used by people who inject drugs and may lead to adverse health outcomes if they are injected.

Methods: This exploratory study used cross-sectional data from the COSMO study, a prospective cohort of out-of-treatment cocaine users carried out in Montréal (Canada) between October 2010 and August 2015. For this analysis, only one visit per participant was selected, that is, the first time the participant reported PO injection during the study.The outcome of interest, "injection of PO residues", was defined as having injected PO residues from a filter and/or a container in the last month. Correlates of this outcome were identified using logistic regression analyses.

Results: Of the 122 participants who reported PO injection during the study period, $41.8 \%$ had injected PO residues. Reporting an unstable source of income (AOR=4.26; 95\% CI: 1.03-17.69), a recent overdose (AOR=5.45; 95\% CI: 1.50-19.88) and a preponderant use of opiates (mostly opiate use versus other drugs excluding alcohol and cannabis) (AOR=2.46; 95\% CI: 1.08-5.63) increased the risk of PO residue injection. The odds of reporting PO residue injection rose by $7 \%$ per unit increase in the score of psychological distress (AOR=1.07 per unit increase; 95\% CI: 1.01-1.12).

Conclusions: The findings of this study suggest that PO residue injection is associated with markers of vulnerability. Further investigation is needed in order to better understand this understudied drug injection practice.
\end{abstract}

Keywords: Injection drug use, drug residue injection, prescription opioids, injection risk behaviors 


\section{Introduction}

Amidst the significant increase of prescription opioid (PO) misuse in recent years, there is growing evidence of intravenous PO administration in several countries. Reports of PO injection have risen worldwide, including in the United States (Davis and Johnson, 2008; Young et al., 2010; Surrat et al., 2011; Lankenau et al., 2012; Black et al., 2013; MateuGelabert et al., 2015), Europe (Partanen et al., 2009; Keijzer and Imbert., 2011; Roux et al., 2011), South Asia (Larance et al., 2011) and Australia (Degenhardt et al., 2006). In Canada, over the past decade, PO injection has gained in popularity among drug users across the country (UHRI, 2013; Leclerc et al., 2013; Firestone and Fischer, 2008; Roy et al., 2011; Roy et al., 2013; Bruneau et al., 2012; Fischer et al., 2006; PHAC, 2014). Data from I-Track, a multisite surveillance system that monitors HIV and hepatitis C virus (HCV) infection rates and associated risk behaviors among persons who inject drugs (PWID) in Canada, revealed that hydromorphone, morphine and oxycodone, either in tablet or capsule form, were injected more often than heroin. These prescription drugs were respectively the second, third and fourth most commonly reported injection drugs used in the last six months (PHAC, 2014). Only cocaine surpassed them as it was the most reported injected drug.

While PO injection has been observed in several parts of the world, its specific injection practices are not well documented. Now, it is generally acknowledged that injection practices may vary depending on the types of substances injected, resulting in more or less serious consequences for the health of users (Gordon and Lowy, 2005). The ethnographic work we carried out in downtown Montréal has allowed us to examine the injection techniques used by PWID to prepare PO tablets or capsules that are designed for oral use 
(Roy et al., 2011). The study findings showed that, due to the physical composition of the two most available forms of POs in the area (Dilaudid ${ }^{\circledR}$ and Hydromorph Contin ${ }^{\circledR}$ ), dissolution was complex and required large amounts of water. This constrained many PO injectors to inject themselves repeatedly during a single injection episode, generally using the same material several times. Also, as opposed to powder cocaine and the white/beige powder heroin available in Montréal, which are easily dissolvable, these PO formulations tended to leave significant amounts of residue in the containers and filters used for injection. The containers and filters were often kept for further use, a practice referred to by users as "doing a wash", as it implies rinsing the used equipment with water to extract the drug residues for injection. Washes were often shared among users who considered them valuable goods they could exchange or offer to other users (Roy et al., 2011).

Injection of drug residues has been previously described among heroin users in the western United States, where black tar was the most prevalent form of heroin (Bourgois, 1998; Koester et al., 2005; Bourgois and Schonberg, 2009). Ethnographers observed that similar to some PO formulations, black tar heroin was not easily dissolvable and left significant amounts of residues in filters used for injection. Overall, ethnographic studies highlighted the vulnerability of PWID who inject residues, showing that this behaviour was mainly practiced by individuals who had unsuccessful income-generating strategies and, consequently had to rely on their own or others' drug residues to relieve opioid withdrawal symptoms (Bourgois, 1998; Bourgois and Schonberg, 2009; Roy et al., 2011).

Drug residue injection entails several serious medical complications including bacterial and fungal infections due to re-use of injection equipment (Gordon and Lowy, 2005; Hope et al., 2008; Kaushik et al., 2011). With respect to PO specifically, residue injection could 
increase the risk of injecting insoluble particles found in pharmaceutical tablets or capsules destined for oral use. Injection of such particles can cause serious health consequences such as pulmonary emboli and ischaemic necrosis (Ng et al., 2015; Roberts, 2002). Finally, drug residue injection can be problematic due to the risks of $\mathrm{HCV}$ transmission when drug residues are shared with other users (Roy et al., 2012). It should be noted that PO residue injection was stated as a possible hypothesis explaining the association between PO injection and HCV transmission in a cohort study of PWID in Montréal (Bruneau et al., 2012). Thus, from a public health perspective, there is a need to document this injection practice and characterize residue injectors in order to better inform harm reduction strategies.

To date, only four studies have looked at the prevalence of drug residue injection, focusing on injecting someone else's drug residue (Koester et al., 2005; Evans et al., 2009; Roy et al., 2012; Le Marchand et al., 2013). To our knowledge, PO residue injection has never been measured or discussed explicitly in epidemiological studies. Yet, in addition to our ethnographic study, PO drug residue injection has been recently qualitatively reported in New York (Mateu-Gelabert et al., 2015), which suggests PO residue injection is not an isolated phenomenon.

The goal of this exploratory study was to estimate the prevalence and correlates of injection of PO residue (either one's own or someone else's) among PO injectors. Secondary analyses were carried out using data from a prospective cohort study on mental health, drug use and HIV/HCV among out-of-treatment (OOT) cocaine users. Informed by ethnographic studies suggesting higher degrees of social and health vulnerabilities among 
residue injectors, we examined the relationship between PO residue injection and sociodemographic characteristics, psychological states and drug use patterns.

\section{Material and methods}

\subsection{The COSMO study}

The COSMO study is a prospective cohort study conducted among OOT cocaine users in Montréal, Canada, between October 2010 and August 2015 among OOT cocaine users. The methodology was described in detail elsewhere (Lévesque et al., 2014). Briefly, to be eligible for the COSMO study, participants had to have used cocaine in the last month, either by smoking crack or by injection. They also had to speak French or English, be able to provide informed consent and be at least 14 years old. Study participants were mainly recruited in community-based programs located in downtown Montréal. After providing informed consent and contact information, participants completed intervieweradministered questionnaires at baseline and during five consecutive follow-up visits, scheduled at three-month intervals. Detailed contact information was updated at each interview and thorough follow-up procedures were used. Participants were paid $\$ 30$ financial compensation for their time, at each interview. This research was approved by the ethical boards of the Faculty of Medicine and Health Sciences at Université de Sherbrooke and of Centre Hospitalier de l'Université de Montréal.

\subsection{Study sample}

The sample included in this analysis was drawn from the COSMO study. Questions about injection of $\mathrm{PO}$ residues among participants reporting $\mathrm{PO}$ injection in the month prior to 
interviews were added to the baseline and follow-up questionnaires on May 1, 2012. COSMO participants who completed questionnaires at that date or thereafter during the study period were eligible for this analysis if they had injected PO in the month prior to interview. For this paper, only one visit per participant was selected, that is, the first time the participant answered yes to the question about PO injection during the study.

\subsection{Measurements}

The outcome of interest for this study was "injection of PO residues," which was defined as having ever injected PO residues from a filter and/or a container in the last month. This included one's own material and material already used by someone else. Based on the literature, correlates of injection of PO residues examined include age (younger than 25 years old vs. older), sex, ethnicity (born in Canada vs. outside), level of education (less than high school vs. higher level), unstable housing (defined as having lived or slept at least once in a shelter or in any place not intended for housing in the past 3 months), reporting a marginal or criminal source of income in the past 3 months (e.g. panhandling, theft, drug dealing), sex work (defined as having vaginal, oral or anal sexual relations with a client in the past month) and recent drug overdose (past 3 months). The preponderant use of opiates, defined as having POs or heroin as the most commonly used drug in the previous month as opposed to any other drug excluding alcohol and cannabis, was also assessed as a surrogate marker of opiate dependency. Additional information was collected to describe patterns of PO injection in the past month, including number of days of injection in a typical week, number of injections during a day and main PO injected. Finally, psychological distress, assessed using the K10 scale (Kessler, 2002), was used as a continuous variable. K10 consists of ten questions on non-specific psychological distress and measures the level of 
anxiety and depressive symptoms a person may have experienced in the previous fourweek period, the final score ranging between 10 and 50 .

\subsection{Analyses}

Descriptive statistics including means, medians, standard deviations and interquartile ranges (IQR) for continuous variables and frequency distributions for categorical variables were used to characterize the study population. Logistic regression analyses were conducted to determine the correlates of PO residue injection among PO injectors. All variables with $p$-values $<0.05$ in bivariate analyses were included in the multivariate model. Following the purposeful selection procedure, significant variables with $p$-values $<0.05$ and those with confounding effects were kept in the final model. A variable was considered confounding if its removal from the model changed a significant coefficient by more than 20\%. The advantage of the purposeful selection method comes when the analyst is interested in risk factor modeling and not just mere prediction (Bursac et al., 2008). The algorithm is used in such a way that, in addition to significant covariates, it retains important confounding variables, resulting in a possibly slightly richer model. Simulation studies demonstrate that the purposeful selection algorithm identifies and retains confounders correctly at a larger rate than other selection procedures. Adjusted odds ratios (AOR) and 95\% confidence intervals (CI) were derived from the final models. SAS 9.3 software was used to perform the analysis.

\section{Results}

A total of 605 cocaine users were recruited in the COSMO study. Of the 491 cocaine users who completed at least one interview between May 1, 2012 and the end of the study, 122 
participants reported injecting POs in the previous month at least once during the study period, and were therefore eligible for this analysis; the majority (101) did so at their first interview. Demographic characteristics and patterns of PO injection are shown in Table 1. Most of the 122 participants were male (82.8\%) and mean age was 37.0 years. In the last month, more than half of participants consumed opiates (54.1\%), namely Dilaudid ${ }^{\circledR}$ or Hydromorph Contin $^{\circledR}(41.8 \%)$ and heroin (12.3\%) as their preponderant drug, followed by cocaine, crack or freebase (38.5\%). Less than a tenth of participants had another preponderant drug such as amphetamines, psychotherapeutics drugs or solvent. Concerning PO injection, Dilaudid ${ }^{\circledR}$ was the main PO injected (65.6\%) followed by Hydromorph Contin $^{\circledR}(29.5 \%)$, and approximately two-thirds of participants injected at least once a week. Multiple injections in a given injection day was common, with slightly more than a third of participants injecting at least 4 times a day.

About four out of ten participants (41.8\%) injected PO residues. Ten factors were examined as correlates of injection of PO residues in bivariate analyses, namely age, sex, ethnicity, level of education, housing, income, sex work, overdose, preponderant use of opiates and psychological distress. Results showed that PO injectors who reported injecting PO residues were significantly more likely ( $p<0.05$ ) to be under 25 years old, to report unstable housing, marginal or criminal sources of income, recent drug overdose and preponderant use of opiates (Table 2). Psychological distress was also positively and significantly $(p<0.05)$ associated with residue injection whereas sex, ethnicity, level of education and sex work were not. The six factors with $p$-values $<0.05$ in bivariate analyses were then included in the multivariate analysis and four were retained in the final model (Table 3). Participants who had marginal or criminal sources of income (AOR=4.26; 95\% CI: 1.03- 
17.69), recent drug overdoses ( $\mathrm{AOR}=5.45 ; 95 \% \mathrm{CI}: 1.50-19.88)$ or consumed opiates as their preponderant drug $(\mathrm{AOR}=2.46 ; 95 \% \mathrm{CI}$ : 1.08-5.63) were more likely to inject $\mathrm{PO}$ residues compared to those who did not. The odds of reporting PO residue injection rose by $7 \%$ per unit increase in the psychological distress score (AOR=1.07 per unit increase; 95\% CI: 1.01-1.12). Despite the fact that age and unstable housing were initially included in multivariate analysis, they did not remained significantly associated with PO residues injection when controlling for other factors aforementioned. Furthermore, giving that they did not constitute confounding factors, they were removed from final multivariate model presented in Table 3, following the purposeful selection procedure.

\section{Discussion}

To our knowledge, this is the first study to assess the prevalence of PO residue injection and identify its correlates among PWID. Our results indicate that $41.8 \%$ of study participants had injected PO residues between May 2012 and August 2015. While no point of comparison exists in the literature, this proportion seems high and is of major concern given the potential adverse health outcomes resulting from this practice. Another important finding is that this injection practice is associated with markers of vulnerability and specific drug use patterns. One marker is income, for which PO residue injectors had greater odds of reporting marginal or criminal activity (such as drug dealing, sex work, panhandling) as their main source of income. This result is consistent with other studies that showed significant associations between illegal or marginal income sources and injection risk behaviours or risky patterns of drug use (Richardson et al., 2010; DeBeck et 
al., 2007; 2011). For instance, in Vancouver, such sources of income have been linked to daily heroin injection (Richardson et al., 2010; Debeck et al., 2007; 2011), injecting in public places (Richardson et al., 2010; DeBeck et al., 2011), binge drug use and syringe sharing (DeBeck et al., 2011). For drug residue injection, it can be hypothesized that, compared to legal income sources, marginal or criminal sources of income likely produce more irregular or weak income streams, which could force PO injectors to fall back on PO residues. These results are consistent with prior ethnographic studies reporting that residue injection is mainly practiced by PWID with low-income sources or unsuccessful income-generating strategies (Bourgois, 1998; Bourgois and Schonberg, 2009; Roy et al., 2011).

PO residue injectors in this study were more likely to report preponderant use of opioid substances (heroin or POs) during the last month. In a study sample of PO injectors, this association may indicate that individuals who inject residues have more severe opioid dependency than other PO injectors. More severe dependency among these PO injectors may explain why they inject drug residues to stave off "dopesickness," particularly when financial resources are scarce (Bourgois, 1998; Bourgois and Schonberg, 2009; Roy et al., 2011).

The observation that PO residue injectors were more likely to have overdosed than other participants suggests that they not only have more severe opioid dependency but also have more intense drug use patterns (Darke et al., 2014). In our sample, overdoses may have been caused by the use of several drugs, and not only opioids, since study participants were polysubstance users (minimally cocaine and POs). It is possible that the 
occurrence of overdoses is a marker of high-risk intensive drug use involving high doses and/or hazardous mixtures of substances.

Finally, our results show that PO injectors who injected residues were more likely to suffer from psychological distress as measured by the K10. Several studies have shown that symptoms of anxiety or depression were associated with drug-equipment sharing behaviours among drug users (Lundgren et al., 2005; Golub et al., 2007; Reyes et al., 2007; Lemstra et al., 2011; German et al., 2012; Armstrong et al., 2013). The mechanisms underlying these relationships are not well understood. A possible explanation for our findings regarding drug residue injection is that PWID do it as a last resort because they are suffering from withdrawal symptoms and have no heroin or other opioids on hand. It has been shown that opioid withdrawal can produce symptoms of anxiety that can heighten levels of distress (American Psychiatric Association, 2013; West and Gossop, 1994). It is also plausible that the experience of suffering from withdrawal symptoms and craving, while feeling forced to relieve these symptoms with what is perceived as a suboptimal alternative to a full dose of opiate, is altogether sufficient to induce a significant rise in level of psychological distress.

Our study is subject to a number of limitations, the first being that this is an exploratory study based on a cross-sectional design. Therefore it is impossible to establish a causal link between the studied covariates and PO residue injection. Also, since the study was based on secondary analyses of the COSMO study, only people who used cocaine in the last month were eligible, thus excluding PO users who did not simultaneously use cocaine. While this might have biased the proportion of study participants who had injected PO residues, it is impossible to know whether that bias pointed to over- or under- 
estimation of prevalence. Furthermore, similar to most studies involving illicit drug-using populations, participants were not randomly recruited, thereby limiting the generalizability of our findings. Finally, data for this study were collected through selfreport, which could have led to recall and social desirability biases. However, the impact of such biases was possibly limited by the short referral period, and the open and nonjudgmental attitudes of the highly experienced study interviewers. Also, it has been shown that self-reported data collected from drug-using populations is generally reliable and valid (Darke, 1998).

\section{Conclusion}

In light of these findings, development of interventions seems imperative to reduce PO residue injection and risk vulnerabilities among PWID in general. Our results highlight the need for better access to low-threshold opioid substitution treatment, which should be facilitated and maximized among PO injectors. This type of treatment has the potential to reduce opioid dependency to more manageable levels which, in turn, could reduce risky behaviors (Mateu-Gelabert et al., 2010). Pharmacological approaches should be complemented by mental health interventions to reduce distress on emotional, cognitive and physiological levels. Furthermore, it is imperative that injection paraphernalia distributed in harm reduction programs be revised to allow safer injection practices among PWID who inject "new" substances. In this regard, it should be noted that public health authorities in Québec have conducted studies to evaluate PO preparation techniques and new drug injection equipment that could produce less drug residue (Noël 
et al., 2015; Leclerc et al., 2015). Prevention messages should also be tailored to inform PWID about the risks of drug residue injection and the methods to inject PO more safely.

In conclusion, residue injection has remained an understudied topic; it has rarely been measured or discussed explicitly in epidemiological studies. Thus it is important to conduct additional studies examining not only its prevalence and correlates, but also the socio-sanitary consequences associated with this injection practice. Such studies could further contribute to tailoring public health interventions aimed at vulnerable PWID. 


\section{Tables}

Table 1: Demographic characteristics and patterns of PO injection among study participants $(n=122)$

\begin{tabular}{|c|c|}
\hline Characteristics of study participants & $\mathbf{N}(\%)$ \\
\hline Age & $37.0(10.2)^{\dagger}$ \\
\hline \multicolumn{2}{|l|}{ Sex } \\
\hline Male & $101(82.8)$ \\
\hline Female & $21(17.2)$ \\
\hline \multicolumn{2}{|l|}{ Ethnicity } \\
\hline Born in Canada & $118(96.7)$ \\
\hline Born outside Canada & $4(3.3)$ \\
\hline \multicolumn{2}{|l|}{ Level of education } \\
\hline Less than high school & $61(50.0)$ \\
\hline Higher than high school & $61(50.0)$ \\
\hline \multicolumn{2}{|l|}{ Housing** } \\
\hline Stable housing & $33(27.1)$ \\
\hline Unstable housing & $89(73.0)$ \\
\hline \multicolumn{2}{|l|}{ Source of income ${ }^{* *}$} \\
\hline Conventional & $18(14.8)$ \\
\hline Marginal or criminal & $104(85.3)$ \\
\hline \multicolumn{2}{|l|}{ Sex work* } \\
\hline Yes & $17(13.9)$ \\
\hline No & $105(86.1)$ \\
\hline \multicolumn{2}{|l|}{ Overdose $\mathrm{e}^{* *}$} \\
\hline No & $107(87.7)$ \\
\hline Yes & $15(12.3)$ \\
\hline \multicolumn{2}{|l|}{ Preponderant use of opiates* } \\
\hline Prescription opioid or heroin & $66(54.1)$ \\
\hline Others & $56(45.9)$ \\
\hline Psychological distress $(\mathrm{K} 10) *$ & $27.2(8.2)^{\dagger}$ \\
\hline \multicolumn{2}{|c|}{ Number of days of PO injection in a typical week* } \\
\hline$\leq 1$ day/week & $43(35.3)$ \\
\hline$>1$ days/week & $79(64.8)$ \\
\hline \multicolumn{2}{|l|}{ Number of PO injections during a day* } \\
\hline 1-3 times/day & $79(64.8)$ \\
\hline$\geq 4$ times/day & $43(35.3)$ \\
\hline \multicolumn{2}{|l|}{ Main PO injected* } \\
\hline Dilaudid $^{\circledR}$ & $80(65.6)$ \\
\hline Hydromorph Contin ${ }^{\circledR}$ & $36(29.5)$ \\
\hline Others & $6(4.9)$ \\
\hline
\end{tabular}


Table 2: Univariate logistic regression analyses of correlates of PO residue injection

\begin{tabular}{|c|c|c|c|c|}
\hline & \multicolumn{4}{|c|}{ PO residue injection* } \\
\hline & $\begin{array}{c}\text { No } \\
\text { n (\%) }\end{array}$ & $\begin{array}{c}\text { Yes } \\
\text { n (\%) }\end{array}$ & OR $(95 \% \mathrm{CI})$ & P value \\
\hline \multicolumn{5}{|l|}{ Age } \\
\hline$<25$ years & $5(33.3)$ & $10(66.7)$ & 1.00 (reference) & \\
\hline$\geq 25$ years & $66(61.7)$ & $41(38.3)$ & $0.31(0.10-0.97)$ & 0.045 \\
\hline \multicolumn{5}{|l|}{ Sex } \\
\hline Male & $58(57.4)$ & $43(42.6)$ & 1.00 (reference) & \\
\hline Female & $13(61.9)$ & $8(38.1)$ & $0.83(0.32-2.18)$ & 0.705 \\
\hline \multicolumn{5}{|l|}{ Ethnicity } \\
\hline Born in Canada & $68(57.6)$ & $50(42.4)$ & 1.00 (reference) & \\
\hline Born outside Canada & $3(75.0)$ & $1(25.0)$ & $0.45(0.05-4.49)$ & 0.499 \\
\hline \multicolumn{5}{|l|}{ Level of education } \\
\hline Less than high school & $36(59.0)$ & $25(41.0)$ & 1.00 (reference) & \\
\hline Higher than high school & $35(57.4)$ & $26(42.6)$ & $0.93(0.46-1.92)$ & 0.854 \\
\hline \multicolumn{5}{|l|}{ Housing** } \\
\hline Stable housing & $25(75.8)$ & $8(24.2)$ & 1.00 (reference) & \\
\hline Unstable housing & $46(51.7)$ & $43(48.3)$ & $2.92(1.19-7.17)$ & 0.019 \\
\hline \multicolumn{5}{|l|}{ Source of income $* *$} \\
\hline Conventional & $15(83.3)$ & $3(16.7)$ & 1.00 (reference) & \\
\hline Marginal or criminal & $56(53.9)$ & $48(46.2)$ & $4.29(1.17-15.70)$ & 0.028 \\
\hline \multicolumn{5}{|l|}{ Sex work* } \\
\hline Yes & $11(64.7)$ & $6(35.3)$ & 1.00 (reference) & \\
\hline No & $60(57.1)$ & $45(42.9)$ & $1.38(0.47-4.00)$ & 0.559 \\
\hline \multicolumn{5}{|l|}{ Overdose $* *$} \\
\hline No & 67 (62.6) & $40(37.4)$ & 1.00 (reference) & \\
\hline Yes & $4(26.7)$ & $11(73.3)$ & $4.61(1.37-15.44)$ & 0.013 \\
\hline \multicolumn{5}{|l|}{ Preponderant use of opiates* } \\
\hline Others & $38(67.9)$ & $18(32.1)$ & 1.00 (reference) & \\
\hline Prescription opioid or heroin & $33(50.0)$ & $33(50.0)$ & $2.11(1.01-4.42)$ & 0.048 \\
\hline Psychological distress (K10)* & $25.7(9.0)^{\dagger}$ & $29.3(6.5)^{\dagger}$ & $1.06(1.01-1.11)$ & 0.019 \\
\hline
\end{tabular}


Table 3: Multivariate logistic regression analyses of correlates of PO residue injection

\begin{tabular}{lcc}
\hline & \multicolumn{2}{c}{ Injection of PO residues* } \\
\cline { 2 - 3 } & AOR $(\mathbf{9 5 \%}$ CI) & P value \\
\hline Marginal or criminal source of income** & $4.26(1.03-17.69)$ & 0.046 \\
Psychological distress (K10)* & $1.07(1.01-1.12)$ & 0.019 \\
Overdose** & $5.45(1.50-19.88)$ & 0.010 \\
Preponderant use of prescription opioid or heroin*** & $2.46(1.08-5.63)$ & 0.032 \\
\hline *Past month. **Past 3 months. & & \\
\hline
\end{tabular}




\section{References}

American Psychiatric Association, 2013. Diagnostic and statistical manual of mental disorders: DSM-5. American Psychiatric Association. Washington, D.C.

Armstrong, G., Jorm, a F., Samson, L., Joubert, L., Nuken, a, Singh, S., Kermode, M., 2013. Association of depression, anxiety, and suicidal ideation with high-risk behaviors among men who inject drugs in Delhi, India. J. Acquir. Immune Defic. Syndr. JAIDS 64, $502-510$.

Black, R.A., Trudeau, K.J., Cassidy, T.A., Budman, S.H., Butler, S.F., 2013. Associations between public health indicators and injecting prescription opioids by prescription opioid abusers in substance abuse treatments. J. Opioid Manag. 9, 5-17.

Bourgois, P., 1998. The moral economies of homeless heroin addicts: Confronting ethnography, HIV risk, and everyday violence in San Francisco shooting encampments. Subst. Use Misuse. 33, 2323-2351.

Bourgois, P., Schonberg, J., 2009. Righteous dopefiend. University of California Press, Berkeley, CA.

Bruneau, J., Roy, É., Arruda, N., Zang, G., Jutras-Aswad, D., 2012. The rising prevalence of prescription opioid injection and its association with hepatitis $\mathrm{C}$ incidence among street-drug users. Addiction. 107, 1318-1327.

Bursac, Z., Gauss, C.H., Williams, D.K., Hosmer, D.W., 2008. Purposeful selection of variables in logistic regression. Source Code Biol. Med. 3, 17.

Darke, S., 1998. Self-report among injecting drug users: a review. Drug Alcohol Depend. 51, 253-263.

Darke, S., Marel, C., Mills, K.L., Ross, J., Slade, T., Burns, L., Teesson, M., 2014. Patterns and correlates of non-fatal heroin overdose at 11-year follow-up: Findings from the Australian Treatment Outcome Study. Drug Alcohol Depend. 144, 5-9.

Davis, W.R., Johnson, B.D., 2008. Prescription opioid use, misuse, and diversion among street drug users in New York City. Drug Alcohol Depend. 92, 267-276.

DeBeck, K., Shannon, K., Wood, E., Li, K., Montaner, J., Kerr, T., 2007. Income generating activities of people who inject drugs. Drug Alcohol Depend. 91, 50-6.

DeBeck, K., Wood, E., Qi, J., Fu, E., McArthur, D., Montaner, J., Kerr, T., 2011. Interest in low-threshold employment among people who inject illicit drugs: Implications for street disorder. Int. J. Drug Policy 22, 376-384. 
Degenhardt, L., Black, E., Breen, C., Bruno, R., Kinner, S., Roxburgh, a, Fry, C., Jenkinson, R., Ward, J., Fetherston, J., Weekley, J., Fischer, J., 2006. Trends in morphine prescriptions, illicit morphine use and associated harms among regular injecting drug users in Australia. Drug Alcohol Rev. 25, 403-412.

Evans, J.L., Hahn, J. a., Lum, P.J., Stein, E.S., Page, K., 2009. Predictors of injection drug use cessation and relapse in a prospective cohort of young injection drug users in San Francisco, CA (UFO Study). Drug Alcohol Depend. 101, 152-157.

Firestone, M., Fischer, B., 2008. A qualitative exploration of prescription opioid injection among street-based drug users in Toronto: behaviours, preferences and drug availability. Harm Reduct. J. 5, 30.

Fischer, B., Cruz, M.F., Rehm, J., 2006. Illicit opioid use and its key characteristics: A select overview and evidence from a Canadian multisite cohort of illicit opioid users (OPICAN). Can. J. Psychiatry 51, 624-634.

German, D., Latkin, C. a, 2012. Boredom, depressive symptoms, and HIV risk behaviors among urban injection drug users. AIDS Behav. 16, 2244-2250.

Golub, E.T., Strathdee, S. a, Bailey, S.L., Hagan, H., Latka, M.H., Hudson, S.M., Garfein, R.S., 2007. Distributive syringe sharing among young adult injection drug users in five U.S. cities. Drug Alcohol Depend. 91 Suppl 1, S30-8.

Gordon, R.J., Lowy, F.D., 2005. Bacterial infections in drug users. New England Journal of Medicine 353, 1945-1954.

Hope, V., Kimber, J., Vickerman, P., Hickman, M., Ncube, F., 2008 Frequency, factors and costs associated with injection site infections: Findings from a national multi-site survey of injecting drug users in England. BMC Infect. Dis. 8, 120.

Kaushik, K.S., Kapila, K., Praharaj, A.K., 2011. Shooting up: the interface of microbial infections and drug abuse. J. Med. Microbiol. 60, 408-422.

Keijzer, L., Imbert, E., 2011. The filter of choice: filtration method preference among injecting drug users. Harm Reduct. J. 8, 20.

Kessler, R.C., Andrews, G., Colpe, L.J., Hiripi, E., Mroczek, D.K., Normand, S.L., Walters, E.E., Zaslavsky, A.M., 2002. Short screening scales to monitor population prevalences and trends in non-specific psychological distress. Psychol. Med. 32, 959-76.

Koester, S., Glanz, J., Barón, A., 2005. Drug sharing among heroin networks:

Implications for HIV and hepatitis B and C prevention. AIDS Behav. 9, 27-39. 
Lankenau, S.E., Teti, M., Silva, K., Jackson Bloom, J., Harocopos, A., Treese, M., 2012. Initiation into prescription opioid misuse amongst young injection drug users. Int. J. Drug Policy. 23, 37-44.

Larance, B., Ambekar, A., Azim, T., Murthy, P., Panda, S., Degenhardt, L., Mathers, B., 2011. The availability, diversion and injection of pharmaceutical opioids in South Asia. Drug Alcohol Rev. 30, 246-54.

Le Marchand, C., Evans, J., Page, K., Davidson, P.J., Hahn, J. a, 2013. Hazardous alcohol consumption among young adult IDU and its association with high risk behaviors. Drug Alcohol Depend. 127, 143-9.

Leclerc, P., Morissette, C., Tremblay, C., Roy, É., 2013. Le volet montréalais du Réseau SurvUDI. Volume 3 - Données au 31 mars 2011. Direction de santé publique Agence de la santé et des services sociaux de Montréal, Montréal.

Leclerc, P., Arruda, N., Morissette, C., 2015. Évaluation de l'acceptabilité de nouveau matériel pour l'injection de médicaments opioïdes. Direction de santé publique du CIUSSS du Centre-Est-de-1’Île-de-Montréal, Montréal.

Lemstra, M., Rogers, M., Thompson, A., Moraros, J., Buckingham, R., 2011. Risk indicators of depressive symptomatology among injection drug users and increased HIV risk behaviour. Can. J. Psychiatry / La Rev. Can. Psychiatr. 56, 358-366.

Lévesque, A., Jutras-Aswad, D., Bertrand, K., Chanut, F., Dufour, M., Lespérance, F., Perreault, M., Vaillancourt, É., Roy, É., 2014. Psychological Distress Increases Needle Sharing among Cocaine users: Results from the COSMO Study. Addict. Res. Ther. S10, 3.

Lundgren, L.M., Amodeo, M., Chassler, D., 2005. Mental health status, drug treatment use, and needle sharing among injection drug users. AIDS Educ. Prev. 17, 525-39.

Mateu-Gelabert, P., Guarino, H., Jessell, L., Teper, A., 2015. Injection and sexual HIV/HCV risk behaviors associated with nonmedical use of prescription opioids among young adults in New York City. J. Subst. Abuse Treat. 48, 13-20.

Mateu-Gelabert, P., Sandoval, M., Meylakhs, P., Wendel, T., Friedman, S.R., 2010. Strategies to avoid opiate withdrawal: implications for HCV and HIV risks. Int. J. Drug Policy 21, 179-85.

Ng, H., Patel, R.P., Bruno, R., Latham, R., Wanandy, T., McLean, S., 2015. Filtration of crushed tablet suspensions has potential to reduce infection incidence in people who inject drugs. Drug Alcohol Rev. 34, 67-73.

Noel, L., Dube, P.-A., Tremblay, P.-Y., Groupe de travail sur la révision du matériel d'injection destiné aux personnes UDI, 2015. Matériel d'injection : réduire les risques 
chez les injecteurs de médicaments opiö̈des. Institut national de santé publique du Québec, Québec.

Partanen, T. a, Vikatmaa, P., Tukiainen, E., Lepantalo, M., Vuola, J., 2009. Outcome after injections of crushed tablets in intravenous drug abusers in the Helsinki University Central Hospital. Eur. J. Vasc. Endovasc. Surg. 37, 704-711.

Public Health Agency of Canada (PHAC), 2014. Summary of key findings from I-Track phase 3 (2010-2012). Centre for Communicable Diseases and Infection Control, Public Health Agency of Canada, Ottawa. Available from: http://www.phacaspc.gc.ca/aids-sida/publication/reports/i-track-phase-3/assets/pdf/i-track-phase-3eng.pdf

Reyes, J.C., Robles, R.R., Colón, H.M., Marrero, C.A., Matos, T.D., Calderón, J.M., Shepard, E.W., 2007. Severe anxiety symptomatology and HIV risk behavior among hispanic injection drug users in Puerto Rico. AIDS Behav. 11, 145-150.

Richardson, L., Wood, E., Li, K., Kerr, T., 2010. Factors associated with employment among a cohort of injection drug users. Drug Alcohol Rev. 29, 293-300.

Roberts, W.C., 2002. Pulmonary talc granulomas, pulmonary fibrosis, and pulmonary hypertension resulting from intravenous injection of talc-containing drugs intended for oral use. Proc. (Bayl. Univ. Med. Cent). 15, 260-261.

Roux, P., Carrieri, M.P., Keijzer, L., Dasgupta, N., 2011. Reducing harm from injecting pharmaceutical tablet or capsule material by injecting drug users. Drug Alcohol Rev. 30, 287-90.

Roy, É., Arruda, N., Bourgois, P. 2011. The growing popularity of prescription opioid injection in downtown Montréal: new challenges for harm reduction. Subst Use Misuse 46, 1142-1150.

Roy, E., Arruda, N., Leclerc, P., Haley, N., Bruneau, J., Boivin, J.F., 2012. Injection of drug residue as a potential risk factor for HCV acquisition among Montreal young injection drug users. Drug Alcohol Depend. 126, 246-250.

Roy, É., Richer, I., Arruda, N., Vandermeerschen, J., Bruneau, J., 2013. Patterns of cocaine and opioid co-use and polyroutes of administration among street-based cocaine users in Montréal, Canada. Int. J. Drug Policy 24, 142-149.

Surratt, H., Kurtz, S.P., Cicero, T.J., 2011. Alternate Routes of Administration and Risk for HIV Among Prescription Opioid Abusers. J. Addict. Dis. 30, 334-341.

Urban Health research Initiative (UHRI). Drug situation in Vancouver. Vancouver: British Columbia Center for Excellence in HIV/AIDS; June 2013. Available from: 
http://www.cfenet.ubc.ca/sites/default/files/uploads/news/releases/war_on_drugs_failing to_limit_drug_use.pdf

West, R., Gossop, M., 1994. Overview: a comparison of withdrawal symptoms from different drug classes. Addiction 89, 1483-9.

Young, A.M., Havens, J.R., Leukefeld, C.G., 2010. Route of administration for illicit prescription opioids: a comparison of rural and urban drug users. Harm Reduct. J. 7, 24. 